\title{
Effects of Addition Clove Oil to Extra Virgin Olive Oil on Microbial Activity for Use as Transformer Oil
}

\author{
Kusnanto Mukti Wibowo ${ }^{1^{*}}$, Royan Royan ${ }^{1}$, Gema Romadhona ${ }^{1}$, Rudi \\ Irmawanto $^{2}$
}

${ }^{1}$ Department of Electromedical Engineering,

Universitas Muhammadiyah Purwokerto, Kembaran, Purwokerto, 53182 INDONESIA

${ }^{2}$ Department of Electrical Engineering,

Universitas Muhammadiyah Surabaya, Mulyorejo, Surabaya, 60113, INDONESIA

*Corresponding Author

DOI: https://doi.org/10.30880/jsmpm.2021.01.01.004

Received 14 November 2021; Accepted 01 December 2021; Available online 08 December 2021

\begin{abstract}
Transformer oil is a liquid insulating material that is used as insulator and as a coolant in transformers. In this study, the addition of clove oil to extra virgin olive oil were performed to determine its effect on antibacterial activity and its usefulness in its ability as a transformer oil. The breakdown voltage test on transformer oil is carried out using various oil temperatures (room temperature and 90oC) because the oil temperature inside the transformer when working/operating can be different, which can be caused by disturbances, excessive loading, and temperature conditions outside the transformer. In addition, the presence of contamination caused by chemical interactions with windings and other solid insulation is catalyzed by high operating temperatures. That causes a gradual change in the original chemical properties of the oil and microbial growth that over time makes it ineffective for use. The method used in this research is by mixing $10 \%, 20 \%, 30 \%$, $40 \%$, and $50 \%$ of clove oil with extra virgin olive oil to determine the change in breakdown voltage and microbial activity. The test results found that, the addition of clove oil has a vital role in inhibiting bacterial growth. The more clove oil added, the better its antimicrobial properties.
\end{abstract}

Keywords: Transformer oil, extra virgin olive oil, clove oil, breakdown voltage, antimicrobial

\section{Introduction}

Transformer oil is a liquid insulating material that is used as insulation and as a coolant in transformers. The transformer oil is a complex structure of the hydrocarbons because transformer oil is obtained from the paraffin or naphthenic base mineral oil. Therefore, it includes paraffin, naphthenes, aromatics at a large amount and other compounds like oxygen, nitrogen and sulfur, etc. at a small amount [1]. An insulating material is required to have the ability to withstand breakdown voltages, while as a cooling function, this transformer oil must be able to reduce the heat that arises. With two important capabilities inherent in transformer oil, it is hoped that the use of transformer oil can protect the transformer from unwanted disturbances [2].

Suppose the transformer oil fails to perform its role as insulation (causing a short circuit). In that case, it can cut off the distribution of electricity because then the transformer does not operate, while without a transformer, electric power cannot be appreciated by consumers. Transformer oil is a crucial component in the electrical power field. In transformer oil, it is necessary to test how much dielectric strength is by evaluating the breakdown voltage value, namely the amount of voltage that can cause an electric jump (flashover) or a spark that causes a short circuit. The test 
is carried out using varying oil temperatures because the temperature of the oil inside the transformer when working/operating can be different, which can be caused by disturbances, excessive loading, and the temperature conditions outside the transformer [3-5].

In addition, the presence of contamination caused by chemical interactions with windings and other solid insulation is catalyzed by high operating temperatures. This causes a gradual change in the original chemical properties of the oil and microbial growth that over time makes it ineffective for use [6].

As a solution, natural esters oil or vegetable oils refined from plant components are introduced. They are less poisonous, biodegradable, and combustible than mineral oil [7]. Mineral oils (MOs) are commonly used in these components to insulate and cool the windings. Furthermore, because to the environmental effect of MOs, these are gradually being replaced with other liquids that are less toxic and give greater security. So, over the past thirty years, research has been conducted in both the academic and corporate arenas with the goal of replacing MOs. As a result, numerous vegetable oils (rapeseed, soya, and sunflower oils) and natural esters (NE) have been produced that are appealing due to their biodegradability, non-toxicity, and environmental friendliness [8].

Clove (Syzygium aramaticum (L.)), a member of the Myrtaceae family, is a commercially grown tree in tropical and subtropical regions [9]. Clove buds, leaves, and stems are utilized for a variety of purposes in the pharmaceutical, food, taste, and fragrance sectors [10]. Clove bud contains roughly 15 to $20 \%$ essential oil by weight, with eugenol being the primary component of clove essential oil. The essential oil of clove bud possesses antibacterial, antifungal, insecticidal, antioxidant, and flavorful effects [11].

Transformer oil that is commonly used in Indonesia is Shell Diala B type petroleum produced by Pertamina. In this study, the researchers wanted to use a mixture of vegetable oils, namely olive oil and clove oil, as oil for transformers at a high temperature which varies to find out how much the value of breakdown voltage. In addition, a test for the antimicrobial content of the oil was also be carried out, considering that clove oil is known to have good antimicrobial properties.

\section{Materials and Method}

In this research, the main tools used include testing breakdown voltages and bacterial inhibition testing. The breakdown voltage test equipment consists of a voltage generator kit which is consists of a step-up transformer with a maximum output voltage capacity of $100 \mathrm{kV}$ and a control panel. A Step-up transformer is used to increase the voltage until the breakdown voltage occurs. A multimeter is used to display the value of the primary voltage, mounted on the primary side of the transformer. A $200 \mathrm{ml}$ test bowl made of fiberglass as a container to put the test oil. Two electrodes (made of copper), spherical in accordance with the VDE standard, and $12.5 \mathrm{~mm}$ in diameter). The heating element is used to heat the oil to the desired temperature by placed heating element in the pan. A grounding rod is used for dissipating residual/neutralizing voltage by attaching the end of the stick to the step-up transformer. While, the tools used for the bacterial test consist of a measuring cup, measuring pipette, petri dish, autoclave, laminar flow, hot plate \& stirrer, and bunsen heater.

The material used in the research is two types of oils, namely extra virgin olive oil and clove oil. The oil is obtained from the market, which is commercial oil. As for the bacteria test requires a bacterial medium (nutrient agar), disc paper, distilled water, and alcohol.

Meanwhile, the bacterial test was carried out by testing before and after mixing extra virgin olive oil with clove oil by varying the addition of clove oil by $10,20,30,40$, and $50 \%$, respectively. This is expected to determine the optimal addition of clove oil, where clove oil is known to have good antimicrobial content. A standard bacterial test will be carried out using Standard Methods Agar (SMA) medium for each mixing oil.

\section{Results and Discussion}

\subsection{Breakdown Voltage Testing}

The first research stage was to test the breakdown voltage value on clove oil \& extra virgin olive oil as oil in transformers. The results are shown in Table 1 below. Table 1 shows the breakdown voltage of clove oil at room temperature. The average value of breakdown voltage of clove oil is $2.8 \mathrm{kV}$. In terms of breakdown voltage, it is quite small value and not too suitable to use as insulation oil. However, it can be used as an insulation liquid by mixing with another oil depending on the purpose. Table 2 shows the breakdown voltage of extra virgin olive oil at room temperature $\left(28^{\circ} \mathrm{C}\right)$ and $90^{\circ} \mathrm{C}$, about 46.73 and $55.89 \mathrm{kV}$, respectively. Compared to clove oil, it was much bigger, about more than 15 times. 
Table 1 - Breakdown voltage testing of clove oil

\begin{tabular}{cc}
\hline \multirow{2}{*}{ No. } & Breakdown voltage $(\mathbf{k V})$ \\
\cline { 2 - 2 } & $26^{\circ} \mathrm{C}$ \\
\hline Test 1 & 0.4 \\
Test 2 & 3.2 \\
Test 3 & 3.3 \\
Test 4 & 3.3 \\
Test 5 & 3.2 \\
Test 6 & 3.2 \\
\hline Average & 2.8 \\
\hline
\end{tabular}

Table 2 - Breakdown voltage testing

\begin{tabular}{ccc}
\hline Oil & \multicolumn{2}{c}{$\begin{array}{c}\text { Breakdown voltage } \\
(\mathbf{k V})\end{array}$} \\
\hline & $28^{\circ} \mathrm{C}$ & $90^{\circ} \mathrm{C}$ \\
\hline Extra virgin olive oil & 46.73 & 55.89 \\
\hline
\end{tabular}

\subsection{Antibacterial Testing}

In bacterial testing, paper discs were used to determine the antibacterial properties of transformer oils. The results were obtained in the form of the diameter of the bacterial inhibition zone. The initial tests were carried out on extra virgin olive oil and pure clove oil, without any additives. It is meant to be a control. The initial test results were obtained in the form of a very wide inhibition zone in clove oil. Meanwhile, in extra virgin olive oil, the inhibition zone is not so clear. This proves that clove oil contains compounds that can inhibit bacterial growth.

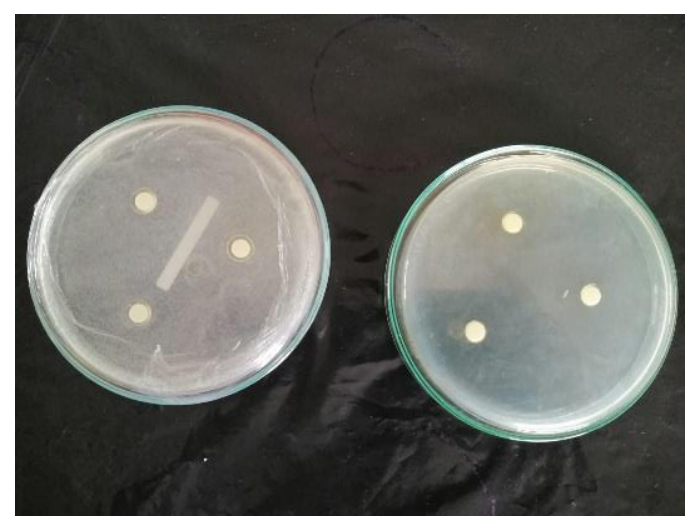

Fig. 2 - Bacterial inhibition zone test results on extra virgin (left) olive oil and clove oil (right)

Furthermore, the inhibition zone testing results on the addition of clove oil to extra virgin olive oil, as shown in the pictures and graphs below. With the addition of clove oil of 10 and $20 \%$, the inhibition zone has not appeared or is not clearly visible. However, after the addition of $30 \%, 40 \%$ and $50 \%$, the bacterial inhibition zone widened from 0.9 , 1.1 , to $2.4 \mathrm{~cm}$. The addition of more clove oil content shows the ability to inhibit bacteria growth, which is getting better as well. This proves that the ability to inhibit bacteria possessed by clove oil works well in any mixture of the oil.

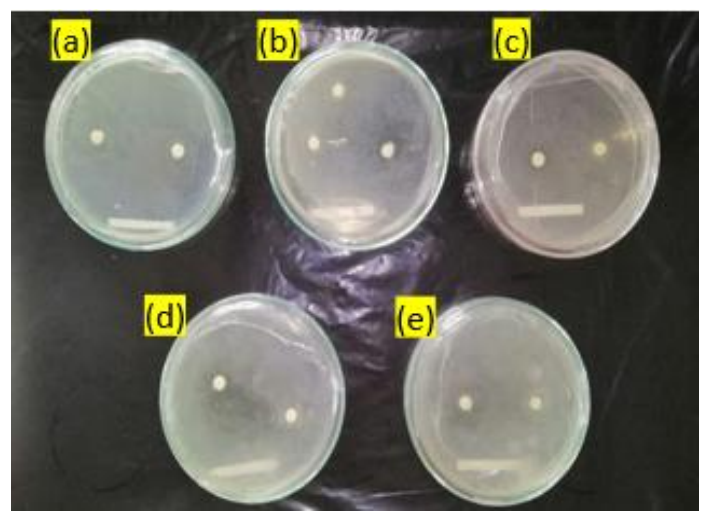

Fig. 3 - The results of the bacterial inhibition zone test using a mixture of extra virgin olive oil with addition of clove oil of (a) $10 \%$; (b) $20 \%$; (c) $30 \%$; (d) $40 \%$; (e) $50 \%$ 


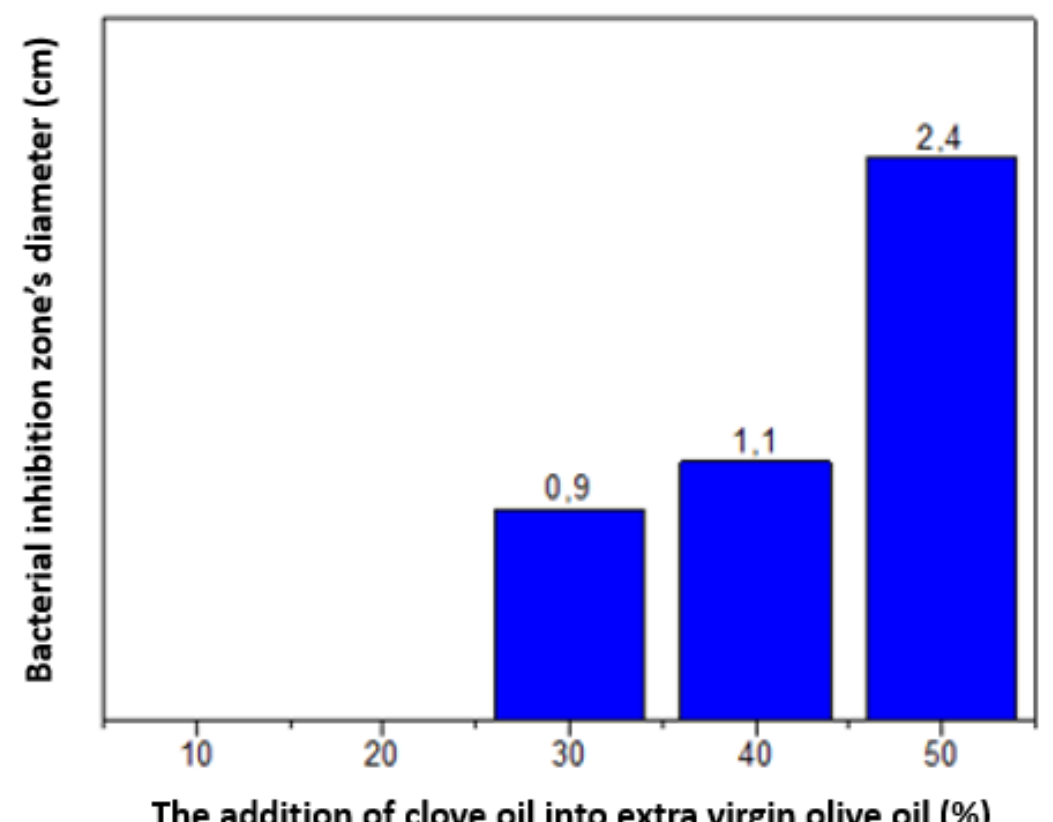

Fig. 4 - Diameter of the bacterial inhibition zone on the effect of adding clove oil

\section{Conclusion}

The addition of clove oil to extra virgin olive oil did not significantly affect the breakdown voltage value. However, the addition of clove oil has a significant role in inhibiting bacterial growth. The more clove oil added, the better its antimicrobial properties. This finding led to future research on how to preserve or treat transformer oil appropriately.

\section{Acknowledgement}

We would like to thank The Institution of Research and Community Services (LPPM) UMP Purwokerto for providing the research grant fund to support this research.

\section{References}

[1] Belkhode, P. N., Ganvir, V. N., Shende, A. C., \& Shelare, S. D. (2021). Utilization of waste transformer oil as a fuel in diesel engine. Materials Today: Proceedings, xxxx.

[2] Srivastava, M., Goyal, S. K., \& Saraswat, A. (2021). Ester oil as an alternative to mineral transformer insulating liquid. Materials Today: Proceedings, 43, 2850-2854.

[3] Senthilkumar, S., Karthick, A., Madavan, R., Arul Marcel Moshi, A., Sundara Bharathi, S. R., Saroja, S., \& Sowmya Dhanalakshmi, C. (2021). Optimization of transformer oil blended with natural ester oils using Taguchibased grey relational analysis. Fuel, 288, 119629.

[4] Vu, T. T., La, T. V., Pham, V. T., Vu, M. K., Huynh, D. C., \& Tran, N. K. (2020). Highly efficient adsorbent for the transformer oil purification by $\mathrm{ZnO} / \mathrm{Graphene}$ composite. Arabian Journal of Chemistry, 13(11), 7798-7808.

[5] Sun, C., Ohodnicki, P. R., \& Stewart, E. M. (2017). Chemical sensing strategies for real-time monitoring of transformer oil: A review. IEEE Sensors Journal, 17(18), 5786-5806.

[6] Samuel, O., Michael, O., \& Ifeanyi, O. (2016). Microbial Contamination of Electrical Power Transformer Oil Obtained from Onitsha, Nigeria. Bioengineering and Bioscience, 4(2), 24-28.

[7] Vukovi, D., \& Tenbohlen, S. (2009). Comparative evaluation of breakdown strength of natural esters and mineral oil. 16th The International Symposium on High Voltage Equipment (ISH-2009), 1-11.

[8] Khaled, U., \& Beroual, A. (2020). DC breakdown voltage of natural ester oil-based Fe3O4, Al2O3, and $\mathrm{SiO} 2$ nanofluids. Alexandria Engineering Journal, 59(6), 4611-4620.

[9] Hossain, M. A., Harbi, S. R. A. L., Weli, A. M., Al-Riyami, Q., \& Al-Sabahi, J. N. (2014). Comparison of chemical constituents and antimicrobial activities of three essential oils from three different brands' clove samples collected from Gulf region. Asian Pacific Journal of Tropical Disease, 4(4), 262-268. 
[10] Cetin Babaoglu, H., Bayrak, A., Ozdemir, N., \& Ozgun, N. (2017). Encapsulation of clove essential oil in hydroxypropyl beta-cyclodextrin for characterization, controlled release, and antioxidant activity. Journal of Food Processing and Preservation, 41(5), 1-8.

[11] Guan, W., Li, S., Yan, R., Tang, S., \& Quan, C. (2007). Comparison of essential oils of clove buds extracted with supercritical carbon dioxide and other three traditional extraction methods. Food Chemistry, 101(4), $1558-1564$. https://doi.org/10.1016/j.foodchem.2006.04.009 